\title{
ВОЗМОЖНОСТИ АВТОМАТИЗИРОВАННОГО РАБОЧЕГО МЕСТА ПРИ РАССЛЕДОВАНИИ ПРЕСТУПЛЕНИЙ
}

\author{
Нуждин А.А.
}

Аннотация: В настоящей статье исследуются особенности производства осмотра, обыска, выемки специального программное обеспечение мобильного автоматизированного рабочего места, которое должно включать, как минимум, следуюшие компоненты:-средства доступа к базе данных о похищенных предметах и ценностях и к базе данных о лицах;- справочную систему (экспертную систему) по тактическим приемам осмотра, обыска и выемки;- программу процессуального оформления результатов;- программу обучения и контроля знаний, умений и навыков сотрудников. Метод или методология исследования: В процессе работы использовались общенаучные и частно-научные методы познания: диалектический, формально-логический, моделирование и структурно-функииональный. Использование мобильного автоматизированного рабочего места возможно не только применительно к следственным действиям. Круг его применения определяется программным обеспечением, объемом и со-держанием баз данных. В связи с этим для повышения универсальности автоматизированного рабочего места в программном обеспечении целесообразно предусмотреть выход во внешние базы данных (дактилоскопические картотеки, картотеки ведения уголовных дел, нормативно-справочной информачии и др.), а также консультачионные и экспертные системы МВД России. Это позволит использовать персональные компьютеры при производстве любого следственного действия и на любой стадии расследования. Применение подобных систем повысит эффективность расследования преступлений, облегчит работу следователя.

Ключевые слова: Возможность, автоматизированное рабочее место, расследование, преступление, следственное действие, кодирование, алгоритмы, паспорт, участок, диск.

Одной из форм использования информационных технологий является создание мобильного автоматизированного рабочего места[1]. Последнее включает в себя портативную электронно-вычислительную машину типа notebook или планшетный компьютер[2] с необходимым программным обеспечением и периферийным оборудованием, а также средства связи и передачи данных.

Мобильное автоматизированное рабочее место можно рассматривать как переносной элемент (интеллектуальный терминал) основного, стационарного автоматизированного рабочего места, находящегося в здании органа внутренних дел, с которого и запрашиваются данные, находящиеся на стационарном компьютере. Вместе с тем следует отметить, что технические характеристики так называемых портативных компьютеров (объем памяти и производительность) не уступают показателям соответствующих моделей стационарных электронных машин. Поэтому в отличие от обычной портативной персональной электронно-вычислительной машины, находящейся в распоряжении следственно-оперативной группы (с целью более оперативной фиксации результатов следственного действия), мобильное автоматизированное рабочее место должно решать более широкий круг задач, в 
том числе возлагаемые и на стационарные автоматизированные рабочие места следователя, а также иметь средства телекоммуникационного доступа к базам данных.

Для мобильного автоматизированного рабочего места состав специального программного обеспечения можно определить исходя из анализа содержательного описания действий следственнооперативной группы и построения соответствующих информационных моделей (входная и выходная информация, формы ее представления, кодирование, алгоритмы преобразования и т.п.) [3]. К примеру, любому виду обыска (обыск помещений, участков местности, автотранспорта) предшествует выполнение общетактических мероприятий: сбор сведений о групповых и индивидуальных признаках искомых предметов, сведений о лицах, у которых планируется производство обыска, подбор участников следственно-оперативной группы, подготовка научно-технических средств и т.п. При прочих равных условиях, данные об искомых предметах, о лице, у которого проводится обыск, об используемых научно-технических средствах будут значительно полнее в случае применения экспертно-консультационных систем и банков данных о лицах и вещах, относимых законам к экстремистским. При составлении плана, включающего приемы производства обыска, существенную помощь может оказать справочная система по тактике производства следственного действия - алгоритм действий в определенных ситуациях.

При производстве осмотра места происшествия также возможно применение персональных компьютеров в решении таких задач, как выбор тактики, научно-технических средств фиксации хода и результатов следственного действия и т.п.

Применительно к производству осмотра, обыска, выемки специальное программное обеспечение мобильного автоматизированного рабочего места должно включать, как минимум, следующие компоненты:

- средства доступа к базе данных о похищенных предметах и ценностях и к базе данных о лицах;

- справочную систему (экспертную систему) по тактическим приемам осмотра, обыска и выемки;

- программу процессуального оформления результатов;

- программу обучения и контроля знаний, умений и навыков сотрудников.

Средства обращения к внешним базам данных позволяют оперативно получать находящуюся в них информацию, а также пополнять эти базы. Для этого нужно реализовать функцию телекоммуникационного доступа с мобильного автоматизированного рабочего места к базам данных стационарных компьютеров, которая состоит в направлении запроса на центральный сервер, откуда он переадресовывается уже непосредственно в информационный центр МВД [4].

Доступ к базе данных о лицах позволит оперативно проверить наличие определенной информации о лицах, попавших в поле зрения правоохранительных органов. В ней содержатся данные о следующих категориях лиц:

- проходящих по делам оперативного учета;

- проходящих по паспортам на административный участок, участок инспекции по делам несовершеннолетних;

- подвергнутых административной ответственности за правонарушения, касающиеся распространению экстремистских материалов, повторное совершение которых влечет уголовную ответственность или иные правовые последствия.

Справочная система по тактическим приемам представляет собой часть программного обеспечения автоматизированного рабочего места, включающую в себя описание типичных следственных ситуаций и программы действий следственно оперативной группы (комплексы следственных, розыскных действий и иных мероприятий, направленных на решение задач каждой следственной ситуации; перечни вопросов, составляющих содержание следственных действий и других мероприятий, проводимых в рамках программ решения следственных ситуаций; ссылки на необходимые акты и инструкции).

Программа процессуального оформления (фиксации результатов) служит для оперативного составления протоколов следственных действий, подготавливаемых на основе готовых форм. Ряд позиций вводной части протокола могут постоянно находиться в памяти компьютера. Иные позиции, например повод для производства следственного действия, вводятся в находящийся в памяти компьютера бланк протокола еще до выезда на место его производства. Это сокращает время ввода данных в автоматизированное рабочее место, позволяет в дальнейшем автоматизировать обработку данных протокола.

Для составления описательной и заключительной частей протокола, содержащих детальное описание обстановки проведения осмотра, обыска, выемки, подробное и точное описание следов, предметов, изъятых в связи с тем, что они могут иметь доказательственное значение, а также других данных, характеризующихся значительным объемом, возможно использовать преобразователи речи в машинный текст. 
После составления протокол выводится на печать через портативный принтер, входящий в состав автоматизированного рабочего места. Отпечатанный в двух экземплярах протокол подписывается следователем, понятыми и другими участниками следственного действия.

При проведении обыска в помещении, где имеется компьютерная техника, «внешние жестские диски» из состава мобильного автоматизированного рабочего места могут применяться при изъятии компьютерной информации, находящейся либо в оперативной памяти интересующего компьютера, либо на каком-нибудь машинном носителе. При производстве обыска различные документы можно прямо на месте путем сканирования поместить в память персонального мини-компьютера в оцифрованном виде, а затем, при необходимости, вывести на принтер или на экран. Особенно заметны преимущества использования «внешних жестских дисков» при изъятии большого объема разнородной информации (переписки в социальных сетях, электронная почта и т.д.). Так, применение портативного сканирующего устройства позволяет быстро оцифровать различные документы, письма и т.п.

Использование мобильного автоматизированного рабочего места возможно не только применительно к следственным действиям. Круг его применения определяется программным обеспечением, объемом и содержанием баз данных. В связи с этим для повышения универсальности автоматизированного рабочего места в программном обеспечении целесообразно предусмотреть выход во внешние базы данных (дактилоскопические картотеки, картотеки ведения уголовных дел, нормативно-справочной информации и др.), а также консультационные и экспертные системы МВД России. Это позволит использовать персональные компьютеры при производстве любого следственного действия и на любой стадии расследования. Применение подобных систем повысит эффективность расследования преступлений, облегчит работу следователя.

\section{Библиография:}

1. Основы информационного обеспечения производства следственных и иных процессуальных действий / Посков Я.А. - М.: Юрлитинформ, 2010. - 144 с.

2. Современное состояние и перспективы использования информационных технологий в раскрытии и расследовании преступлений. Автореф. дис. ... канд. юрид. наук / Яковенко И.Н. - Краснодар, 2005. - 22 с.

3. Посков Я.А. Структура информационного обеспечения производства следственных действий // Актуальные проблемы борьбы с преступностью на современном этапе: сборник материалов Всероссийской научно-практической конференции, посвященной 90 -летию образования Дальневосточного юридического института МВД России, 22-23 сентября 2011 г.. - Хабаровск: Изд-во Дальневост. юрид. ин-та МВД России, 2011. - С. 137-144.

4. Яковенко И.Н. Некоторые вопросы информатизации правоохранительных органов // Закон и судебная практика. Сборник научных статей ученых-юристов Краснодарсткого края и Республики Адыгея. - Краснодар: Изд-во Краснодар. юрид. ин-та МВД России, 2002. - С. 412-413.

\section{References (transliterated):}

1. Osnovy informatsionnogo obespecheniya proizvodstva sledstvennykh i inykh protsessual'nykh deistvii / Poskov Ya.A. - M.: Yurlitinform, 2010. - 144 c.

2. Sovremennoe sostoyanie i perspektivy ispol'zovaniya informatsionnykh tekhnologii v raskrytii i rassledovanii prestuplenii. Avtoref. dis. ... kand. yurid. nauk / Yakovenko I.N. - Krasnodar, 2005. - 22 c.

3. Poskov Ya.A. Struktura informatsionnogo obespecheniya proizvodstva sledstvennykh deistvii // Aktual'nye problemy bor'by s prestupnost'yu na sovremennom etape: sbornik materialov Vserossiiskoi nauchnoprakticheskoi konferentsii, posvyashchennoi 90-letiyu obrazovaniya Dal'nevostochnogo yuridicheskogo instituta MVD Rossii, 22-23 sentyabrya 2011 g.. - Khabarovsk: Izd-vo Dal'nevost. yurid. in-ta MVD Rossii, 2011. - S. 137-144.

4. Yakovenko I.N. Nekotorye voprosy informatizatsii pravookhranitel'nykh organov // Zakon i sudebnaya praktika. Sbornik nauchnykh statei uchenykh-yuristov Krasnodarstkogo kraya i Respubliki Adygeya. Krasnodar: Izd-vo Krasnodar. yurid. in-ta MVD Rossii, 2002. - S. 412-413 